\title{
Storytelling as a Teaching Tool: The Importance and Benefits for Business English Students
}

\author{
Tatjana Koropec* \\ Faculty of Economics and Business University of Maribor, Slovenia
}

*Corresponding Author: Tatjana Koropec, Faculty of Economics and Business University of Maribor, Slovenia

\begin{abstract}
Narrating or storytelling is one of the oldest ways of human communication, and still today it has been successfully used as an effective pedagogical tool in the development of language skills in the native and the foreign language. This article aims to present the tips to the teachers as they are preparing their students for storytelling performance during their tertiary education and their future career life in the corporate environment. Business English students need a variety of skills for their future endeavours and stories can add to their learning process - since storytelling is a synthesis of all the important aspects of a language learning process: learning vocabulary, improving pronunciation, understanding grammatical structures, developing oral fluency and mastering emotional intelligence.
\end{abstract}

Keywords: Business English, emotional intelligence, narrating, storytelling.

\section{INTRODUCTION}

According to the Online Cambridge Dictionary, storytelling is the "activity of writing, telling, or reading stories". It is a very old form of teaching and learning. Nancy Anderson wrote in her book that "People have always told stories; it is the oldest form of remembering. In ancient times, long before written language was developed, people told stories to preserve the history, traditions, desires, and taboos of their social groups. Each generation told their stories to the next, which in turn told the stories to the youth of the generation that followed them." (2005, p. 81).

Even today -while we are suffocating with all kinds of modern technology - there are still places in this world and remote societies where storytelling is the only way of schooling.

The writer, Elif Shafak is suggesting: "Stories bring us together, untold stories keep us apart." And further: "We are made of stories - those that have happened, those that are still happening at this moment in time and those that are shaped purely in our imagination through words, images, dreams and an endless sense of wonder about the world around us and how it works." (2020, p. 9)

No matter what situation we are in storytelling is a very useful skill one can possess, or develop and master. However, this fact is even more relevant for students of Business English and if only two different aspects were considered but there are many more.

\subsection{The language}

Students are learning a foreign language - in our case English. They had been learning the language for at least 8 years or more (some students even up to 15 years) before they enrolled at the tertiary level of education (Faculty of Economics and Business). At that point, most of the students have reached at least level B2 according to the CEFR (Common European Framework of Reference for Languages) and they

- "Can understand the main ideas of complex text on both concrete and abstract topics, including technical discussions in his/her field of specialisation.

- Can interact with a degree of fluency and spontaneity that makes regular interaction with native speakers quite possible without strain for either party.

- Can produce clear, detailed text on a wide range of subjects and explain a viewpoint on a topical issue giving the advantages and disadvantages of various options." 
Since they started studying Economics and Business they have been digging into very specific topics and expanding their vocabulary into new areas - such as accounting, e-marketing, advertising, logistics, etc. Being Independent or Proficient Users of the English Language they do not struggle with grammatical issues and sentence structure. Moreover, they do not need to put so much effort into building a story and finding basic or appropriate vocabulary. On the contrary, in all those past years they have become self-confident about speaking the foreign language, can play with the words and easily tell a story.

\subsection{Economics and Business}

Researching about economic and business matters and studying for their future career are bringing students to new horizons and open new challenges - how to act and react in the business world, how to prepare for a meeting, to conduct negotiations or deliver a successful presentation. A dry and abstract business report with many numbers, graphs, and charts can be translated into a compelling story that could engage the audience intellectually and emotionally. Nowadays, like Business English students they can acquire and practice these skills and strategies, and later on, as upcoming businesswomen and men, they can apply and take advantage of these particular skills and strategies. And this is the second aspect where students can utilize the power of a well-presented and told story.

This article aims to share tips to the teachers as they are preparing their students for storytelling performance during their tertiary education and their career life in the corporate environment.

\section{PROCESS - How TO SUCCESSFULlY PREPARE FOR AND DELIVER A STORY?}

Business English students need a variety of skills for their future endeavours and stories can add to their learning process.

- Students strengthen their thinking strategies - like summarising, comparing, forecasting, problem-solving, planning, assuming, role-playing, etc.

- They develop new strategies for learning English - for example, learning and memorizing new words, specialized vocabulary, idioms, and phrases, learning and rehearsing new language structures, guessing the meaning of new words, memorising.

- They bring their study skills to a more advanced and effective state (for example writing and structuring; reporting, synthesizing and presenting; understanding and interpreting numbers, quantities, trends, charts, and graphs; analysing data, selecting information and coming to a conclusion or reaching a decision).

- Students develop a variety of soft skills such as active listening, attentive listening, asking wellformed questions, when and how to join the conversation, paying attention to details, controlling body-language, and keeping eye-contact.

- They develop social and personal skills: self-confidence and self-esteem, a spirit of community and cooperation in the group, positive features, and personal traits that are present in stories (like compassion, honesty, courage).

- By reading, researching, telling stories, and listening to stories students expand their awareness and appreciation of other cultures.

Students in my classes (Business English students) usually do not tell and retell folk stories, traditional stories, legends, and similar. They write their own stories after conducting thorough research about a product, a service, a brand, an entrepreneur, a company, a business person, a movement or trend, or other topics that can be of some significance to them. After researching and selecting their topic they write a story considering the following general guidelines:

\subsection{When Preparing, Consider...}

"Human beings master the basics of storytelling as young children and retain this capability throughout their lives." Stephen Denning (2010, p.7)

\subsection{Story Structure}

Students were introduced to stories at an early age which was sparking a passion for reading by themselves and later telling and retelling stories to others. They have a rough idea of the enormous possibilities of a story structure. 
Psychologist T. A. Harley (2001) concluded that "There is no agreement on story structure: virtually every story grammatician has proposed a different grammar,"after he had thoroughly and extensively researched the available academic literature on the structure of stories.

However, for the sake and the purpose of the storytelling task students are suggested the following structures:

- The Three-Act Structure: The setting - The Confrontation - The Resolution. With alternative wording: a presentation - a climax - an end, or: a problem - an insight - a mission.

- 5 WH questions Structure: Where and When, Who, What, Why (and we can add How).

- In Medias Res Structure (which is Latin for "in the midst of things").

\subsection{Content}

Students are free to select their topic and since their field of studies covers the topics in business and economics they tend to choose topics about their favourite product, a service, a brand, or a company. They present life stories of outstanding entrepreneurs or inspirational business people. They can introduce a movement, a new trend or any other topic which may be of some importance to them.

In storytelling, it is not so much what you tell as it is how you tell it. Therefore, after choosing the right content, researching the available authentic material, and gathering factual information, students select the important passages, the key information, and write their own stories in English. They select one of the suggested story structures, organise their ideas in a simple and clear plot, use a congruous and consistent style, and add a strong emotional element. Considering all these students are most likely to write a smoothly flowing story with well-selected vocabulary and adequate grammatical structures.

\subsection{Practice, Practice, Practice}

A storyteller must be a good performer to draw the full attention of the audience. A story is told not read and therefore it should be learned by heart. This act requires much rehearsal. With the right techniques and some practice, a student can remember the story and tell it smoothly.

Students practice telling a story numerous times, aloud to themselves or a friend. They try different interpretations and play with their voice. They can record their storytelling. They can break the story into smaller parts and write the key elements on a small piece of paper. They can use it as a reminder of the next sequence. Body language, eye-contact, facial expression, miming, and gestures should be synchronically supporting the story. At this stage of practising there is one exercise which we conduct during the lecture: all the students are given the same story and each person would prepare his or her own performance or interpretation of the story. In such a way students are researching the variety of possibilities and the potential effects of different interpretations.

\subsection{During Storytelling}

After successful rehearsal students are ready to present their stories in front of the audience, in front of other students. Firstly, they prepare the audience for listening and set the scene. The new vocabulary, phrases, and idioms could be elicited and explained before or after the story is told. Students usually explain new vocabulary after telling the story.

Every student develops their own art of performing and use their unique style of narrating. The selection of words and language patterns, the body-language and mimics, the volume, tempo, and pitch of their voice should all support the story content. The basic rule though is to speak slowly and clearly. While telling stories students do not use computers, any visual aids, or any other items, but they may have a note card with key elements to remember the structure.

While the story is being told the other students are listening attentively, write questions, ideas, and insights. They may be given a task: listening for particular information, making a prediction (about a character, about the ending), observing and learning about qualities that make storytelling effective.

\subsection{After Storytelling}

There are a variety of follow-up activities and exercises which could be conducted immediately after the story is told. From the listening part, we can move to: 
- Vocabulary: usually the first thing students are eager to do is eliciting new words, idioms, and phrases. Students listeners are invited into a discussion about the meanings of those new words. The storyteller would prepare handouts with a list of new expressions, words and idioms and their explanation in English.

- Speaking: students can retell the story in their own words, summarise the story, describe a character, compare a story to their background knowledge, share their first-hand experience on the topic, answer the question: What would you have done?

- Writing: summarizing or rewriting a story, freewriting about the topic, rewriting a story in the first-person perspective.

- Reflection: students are asked to evaluate and reflect on their storytelling in order to improve. Some questions to contemplate: How can you measure your success? How can you learn from your mistakes? How can you test and evaluate which storytelling technique is working for you? How can you gather feedback on how well your message is coming across? In the reflection discussion, both the storyteller and the listeners are participating and exchanging their points of view.

- Material collection: creating files with topics - Entrepreneurs, Advertising, Customers Behaviour, Companies, Brands, Products, Services, Culture, etc. Students are gathering and building up material for studies which is open and accessible to any member of the group.

Additionally, there are some other ideas for the follow-up activities - for example:

- Adapting well-known stories: an example - Little Red Riding Hood written or retold in a new genre such as a romance, a crime, a science-fiction or in the language of a lawyer, a marketer, an artist, a businessman, a manager, an entrepreneur, a free-lancer, a secretary,...

- Watching a video with no sound and telling a story.

- An open-end story: a student presents the beginning of the story and the listeners continue the story, they tell or write the ending of the story; the listeners ask questions about the missing information.

\section{Conclusion: Benefits Of Telling AND Listening To Stories}

At the beginning of the article, I emphasised that students need to develop a variety of skills for their future endeavours and by telling stories their learning process can be inspired afresh and motivated anew. Stories are motivating and can stimulate language learning by enhancing students' vocabulary and acquiring new language structures. Telling and listening to stories implant an idea of curiosity and a sense of joy in words and language which make students want to read more. Besides increasing verbal proficiency and oral communication skills, students are developing their listening and writing skills. Therefore, by storytelling and the supplementary activities and exercises all four basic language skills are addressed and enhanced.

Both listening to and telling stories energise and vivify the powers of imagination and creativity, which are keys to comprehension and higher levels of thinking. Additionally, with imagination and creativity bursting students consider new and unusual ideas, think outside the box, and go off the beaten tracks.

Furthermore, storytelling and listening are cultivating students' emotional and social intelligences. Students are aware that they are in a safe environment, where cooperation, trust, and confidence are performed. They are willing to express their thoughts and ideas, their fears and feelings since they know it is an anxiety-free community. Through learning and sharing tales, providing feedback, and conducting active participation a group develops a spirit of community and cooperation. Students develop their confidence and increase their self-image and self-worth when they receive positive feedback and attention from their colleagues.

Stories teach us about essential human traits like compassion, honesty, fairness, and help us build strong personalities and good character. By listening to stories students attain an insight into different patterns of human behaviour.

In many ways, storytelling enhances intercultural awareness, understanding, and communication. Stories allow students to experience other cultures and to explore their own cultural roots. They learn 
about different traditions, customs, and values, and gain insight into universal life situations and in such a way they can understand that wisdom is common to all people around the world.

Referring to all the listed benefits storytelling is a highly important skill for Business English students to master during their studies in order to be confident when presenting, negotiating, and meeting in English once they enter into the business world and climb up the corporate ladder.

\section{REFERENCES}

[1] Anderson A. Nancy. 2005. Elementary Children's Literature. London: Pearson. p.81.

[2] Cambridge dictionary on line. Retrieved from https://dictionary.cambridge.org/dictionary/english/storyt elling

[3] CommonEuropeanFrameworkof Reference for Languages. Retrieved from https://www.coe.int/en/web/c ommon-european-framework-reference-languages

[4] Denning, S. (2010). The Leader's Guide to Storytelling. Hoboken, NJ: Jossey-Bass. P.7.

[5] Harley, T. A. (2001). The psychology of language: From data to theory (2nd ed.). Psychology Press. p.381.

[6] Smith, P. The Structure of a Story. Retrieved from https://fs.blog/2014/02/the-structure-of-a-story/

[7] Shafak, E. (2020). How to stay sane in an age of division. London: Wellcome Collection. P. 9

\section{AUTHOR'S BIOGRAPHY}

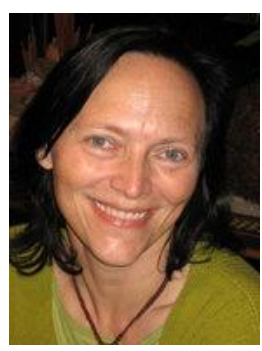

Tatjana Koropec, is a General English and Business English teacher at the Faculty of Economics and Business, University of Maribor, Slovenia. She has a degree in the Slovene language and literature and the English language and literature. She is fascinated by the interplay between language, culture and thought and has been researching topics connected to those areas.

Citation: Tatjana Koropec. "Storytelling as a Teaching Tool: The Importance and Benefits for Business English Students" International Journal of Humanities Social Sciences and Education (IJHSSE), vol 8, no. 2, 2021, pp. 105-109. doi: https://doi.org/10.20431/2349-0381.0802009.

Copyright: () 2021 Authors. This is an open-access article distributed under the terms of the Creative Commons Attribution License, which permits unrestricted use, distribution, and reproduction in any medium, provided the original author and source are credited. 